\title{
The diagnosis of neurocysticercosis A closed question?
}

\author{
Luís dos Ramos Machado
}

In this issue, Arquivos de NeuroPsiquiatria publishes three articles about the diagnostic aspects of neurocysticercosis (NC). I think it is very important to discuss some aspects of this disease.

WHO considers that $\mathrm{NC}$ is the main disease of the central nervous system (CNS) caused by parasites ${ }^{1}$. NC may be the consequence of two distinct morphological forms of the larval form of Taenia solium: Cysticercus cellulosae and Cysticercus racemosus ${ }^{2}$. These two different morphological forms are responsible for two very distinct clinical presentations of $\mathrm{NC}$, although they may coexist in some patients.

Most publications about NC are concerned with the more frequent parenchymatous form of NC caused by Cysticercus cellulosae. This form has a scolex detectable on computed tomography (CT) or magnetic resonance imaging (MRI). The evolutive phases of the cysts can be seen over 4 to 5 years on CT or MRI; epilepsy is the usual clinical manifestation of this condition, which has an estimated mortality rate of $0.5 \%$.

On the other hand, NC caused by Cysticercus racemosus is usually seen in skull base cisterns or in the Sylvian fissure. This manifestation seems to be more rare, although some authors report a frequency as high as $45 \%$. Charateristically, these cysts have no scolex; they may persist in the CNS for 15 to 20 years; and intracranial hypertension is the most frequent clinical presentation. The management of the chronic inflammation and the complications caused by this meningitis are usually very difficult, and the mortality rate can be up to $33 \%{ }^{3}$.

In 2001, Del Brutto et al. published a consensus about diagnostic criteria of $\mathrm{NC}^{4}$. They adopted a quite rigid hierar- chy of criteria, classified as absolute, major, minor and epidemiologic. In practice, only the absolute criterion is used to include patients in almost all studies of NC reported in the recent literature.

By this consensus, the absolute criterion for the diagnosis and considered by them as pathognomonic of $\mathrm{NC}$ is the detection of a scolex inside a cyst by CT or MRI. However, C. racemosus doesn't have a scolex. So, patients with this form of the disease do not fulfill the absolute criterion and tend to be excluded, although this is a more severe form of NC.

Even in the parenchymatous form of $\mathrm{NC}$, the use of this absolute criterion may be hazardous. About 15\% of patients with NC have a unique cysticercus in CNS. During the degeneration phase of the cyst, its image may lose its classical characteristics, and may be confused with a granuloma, abscess or even a metastatic neoplasm. Furthermore, in the final phase of degeneration, cysts may disappear on $\mathrm{CT}$ or MRI for a period as long as 12 to 14 months, making the diagnosis by image criteria more difficult ${ }^{5}$. This can be illustrated in the Fig 3 from the paper of Abraham et al. published in this issue.

One can argue that other criteria can be used for the diagnosis of NC. That is true. But some of these criteria are quite difficult to be accepted at least in the form they have been proposed. The EIBT test to detect specific anti-Taenia antibodies is considered as a major criterion although it is only a serological test. Meanwhile, the traditional contribution of CSF analysis for the diagnosis of $\mathrm{NC}$, object of many publications in decades, is almost entirely ignored. The ELISA test in the CSF${ }^{6}$, the only one considered, is listed as a minor
DIAGNÓSTICO DA NEUROCISTICERCOSE: UMA QUESTÃO FECHADA ?

MD, PhD, Department of Neurology, São Paulo University Medical School. São Paulo SP, Brazil. 
criterion, with a similar diagnostic value as calcifications in thigh or calf muscles seen on plain X-ray films ${ }^{4}$.

It is very hard to accept that, unlike all other infectious diseases of the CNS, the diagnosis of NC must be made without a vigorous contribution of CSF analysis.

Maybe the generalized use of Del Brutto et al. criteria have created some distortion in the present perception of NC. Increasing the frequency of the clinical forms related to parenchymatous cysts and excluding the clinical manifestations caused by extraparenchymatous forms, diagnosis of NC becomes almost exclusively the diagnosis of the epileptic form of NC. In fact, WHO reports that epilepsy is observed in 50 to $60 \%$ of patients with NC. However, in recent studies such as that of Abraham et al., epilepsy is the main clinical manifestation in $95 \%$ of NC patients.

On the other hand, racemous forms of Taenia larvae may cause intracranial hypertension, chronic meningitis, hydrocephalus, arachnoiditis and vasculitis sometimes with stroke ${ }^{7}$, as shown by Castro-Lima et al. images, also published in this issue. The diagnosis of these forms may be achieved with high sensibility and specificity only by CSF analysis. Besides the classical immunological tests searching anti-Taenia antibodies in CSF, tests to detect Taenia antigens, as reported by Abraham et al. ${ }^{8}$, and genomic sequences of Taenia by $\mathrm{PCR}^{9}$ are also available.
I believe that an urgent, extensive and comprehensive revision of the diagnostic criteria of $\mathrm{NC}$ is mandatory. New diagnostic methods and a careful analysis of the large experience acquired by many groups in many countries worldwide must be considered in order to achieve a new consensus on the diagnosis of $\mathrm{NC}$.

\section{REFERENCES}

1. World Health Organization, 2002. Control of Neurocysticercosis: Report by the Secretariat. Fifty-fifth World Health Assembly; Provisional Agenda item 13.18. Washington, DC: World Health Organization. Report no. A55/23.

2. Rabiela-Cervantes T, Rivas-Hernandes A, Castillo-Medina S, Gonzalez-Angulo A. Pruebas morfológicas de que $C$. cellulosae y $C$. racemosus son larvas de Taenia solium. Arch Invest Med (Mexico) 1985;16:81-92.

3. Colli BO, Carlotti CG, Assirati JA Jr., Machado HR, Valença M, Amato MCM Surgical treatment of cerebral cysticercosis: long-term results and prognostic factors. Neurosurg Focus 2002;12:1-12.

4. Del Brutto OH, Rajshekhar V, White AC Jr., et al. Proposed diagnostic criteria for neurocysticercosis. Neurology 2001;57:177-183.

5. Machado LR, Nóbrega JPS, Barros NG, Livramento JA, Bacheschi LA, SpinaFrança. Computed tomography in neurocysticercosis. Arq Neuropsiquiatr 1990;48:414-418.

6. Machado LR, Livramento JA, Vaz AJ, et al. Ig intrathecal synthesis and specific antibody index in patients with neurocysticercosis. Arq Neuropsiquiatr 2002;60:395-399.

7. Barinagarrementeria F, Cantú C. Frequency of cerebral arteritis in subarachnoid cysticercosis. An angiographic study. Stroke 1998;29:123-125.

8. Abraham R, Pardini AX, Vaz AJ, Livramento JA, Machado LR. Arq Neuropsiquiatr 2004;62:756-760.

9. Almeida CR, Ojopi EP, Nunes CM, et al. Taenia solium DNA is present in the cerebrospinal fluido of neurocysticercosis patients and can be used for diagnosis. Eur Arch Psychiatry Clin Neurosci 2006;612:1-4. 